\title{
Comparison of postoperative pain between patients who underwent primary and repeated cesarean section: a prospective cohort study
}

\author{
Guangyou Duan ${ }^{\dagger}$, Guiying Yang ${ }^{\dagger}$, Jing Peng, Zhenxin Duan, Jie Li, Xianglong Tang and Hong Li ${ }^{*}$ (D)
}

\begin{abstract}
Background: The differences in post-operative pain are unclear between the primiparas who underwent a primary cesarean section and multiparas who underwent their first repeat cesarean section. The study aimed to explore the possible differences in postoperative pain between primiparas and multiparas.

Methods: A prospective cohort study was performed only including women who underwent cesarean deliveries under spinal anesthesia. Postoperative patient-controlled intravenous analgesia (PCIA) was administered to all subjects with $0.2 \mathrm{mg} / \mathrm{kg}$ hydromorphone and $4 \mathrm{mg} / \mathrm{kg}$ flurbiprofen; the pump was programmed as $2.0 \mathrm{~mL} / \mathrm{h}$ background infusion with a loading dose of $1 \mathrm{~mL}$ and a lockout period of $15 \mathrm{~min}$. Postoperative incision and visceral pain intensity were evaluated using the visual analogue scale, and inadequate analgesia was defined as a visual analogue scale score $\geq 40$ during $48 \mathrm{~h}$ post-operation. Additionally, the patients' pain statuses in postoperative week 1 and week 4 were also assessed during follow-up via telephone.

Results: From January to May 2017, a total of 168 patients (67 primiparas and 101 multiparas) were included. The relative risk for multiparas to experience inadequate analgesia on incision pain was 0.42 ( $95 \%$ Cl: 0.25 to 0.74 ) compared to primiparas. In patients aged $<30$ years, inadequate analgesia on visceral pain was higher in multiparas than in primiparas (RR, 3.56 [1.05 to 12.04], $P=0.025$ ). There was no significant difference in the combined incidence of inadequate analgesia in both types of pain between the multiparas and primiparas (33.7\% vs. 40.2\%, $P=0.381)$. No difference was found in PCIA use between the two groups $(111.1 \pm 36.0 \mathrm{~mL}$ vs. $110.9 \pm 37.3 \mathrm{~mL}$, $P=0.979$ ). In addition, a significantly higher incidence of pain was noted 4 weeks post-surgery in primiparas than that in multiparas $(62.2 \%$ vs. $37.7 \%, P=0.011)$.
\end{abstract}

Conclusion: Multiparas who underwent their first repeat cesarean section have a lower for inadequate analgesia on incision pain during the first $48 \mathrm{~h}$ after surgery than primiparas. Multiparas aged under 30 years may be more prone to experiencing postoperative inadequate analgesia on visceral pain.

Trail Registration: ClinicalTrial.gov: NCT03009955, Date registered: December 30, 2016.

Keywords: Cesarean section, Postoperative pain, Analgesia, Primiparas, Multiparas

\footnotetext{
* Correspondence: Ih78553@163.com

${ }^{+}$Guangyou Duan and Guiying Yang contribute equally to the project and both are considered as first authors.

Department of Anesthesiology, Xinqiao Hospital, Army Medical University, Chongqing 400037, China
}

(c) The Author(s). 2019 Open Access This article is distributed under the terms of the Creative Commons Attribution 4.0 International License (http://creativecommons.org/licenses/by/4.0/), which permits unrestricted use, distribution, and reproduction in any medium, provided you give appropriate credit to the original author(s) and the source, provide a link to the Creative Commons license, and indicate if changes were made. The Creative Commons Public Domain Dedication waiver (http://creativecommons.org/publicdomain/zero/1.0/) applies to the data made available in this article, unless otherwise stated. 


\section{Background}

Cesarean section is the most common impatient surgical procedure globally. In 2016, the cesarean delivery rate in the United States was 31.9\% [1]. In China, the annual cesarean delivery rate reached $41.1 \%$ in 2016 after relaxation of the one child policy [2]. However, despite the numerous measures that have been developed to manage postoperative pain, inadequate analgesia after cesarean section is common, with an incidence of nearly 50\% [3-6]. Therefore, post-operative pain treatment remains a considerable clinical challenge in acute postoperative care during cesarean section. Inadequate postoperative pain management is associated with persistent pain, delayed functional recovery, and a longer hospital stay, which increase medical expenses, and is becoming a public health issue [7, 8]. Therefore, the treatment of pain after a cesarean section remains unresolved.

In China, a new clinical challenge for the treatment of pain after a cesarean section has emerged, following the implementation of China's new national two-child policy $[9,10]$. Many obstetric patients with known history of previous cesarean section are scheduled to undergo repeated cesarean section. Because repeated cesarean sections is common in very aged individuals and are known to have higher operative difficulties and longer surgical times due to severe adhesions [11, 12], we speculated that there would be a difference in pain control during the postoperative period between the patients who underwent repeated and primary cesarean sections; and that the multiparas may have a higher risk of receiving inadequate analgesia.

Intravenous or intrathecal analgesia with opioids is recommended and is a commonly used method for pain treatment after cesarean delivery. However, currently, most female patients receive a one-size-fits-all approach for analgesia after cesarean section, regardless of primiparas or multiparas. In the recent Practice Guidelines for Obstetric Analgesia and Anesthesia, there was no specific explanation for the possible difference in postoperative pain between the patients who underwent repeat and primary cesarean sections $[13,14]$. There are limited studies focusing on this issue. In addition, exploring the inter-individual variability in the degree of pain, and accurately targeting treatment in women who may experience inadequate analgesia may improve clinical outcomes $[15,16]$. Therefore, the current prospective cohort study included patients who were scheduled to undergo primary or repeated cesarean sections to investigate the potential difference in postoperative pain between them.

\section{Methods}

\section{Patients}

This study was conducted according to the STROBE recommendations $[17,18]$. The study protocol was approved by the Institutional Ethics Committee of Xinqiao
Hospital, Third Military Medical University, Chongqing, China. Prior to the enrollment of patients, written informed consent was obtained from all the patients, and the study was registered on Clinicaltrial.gov (ID: NCT03009955).

Patients were included according to established inclusion and exclusion criteria. From January to May 2017, 168 Chinese patients, aged 20 to 40 years scheduled to undergo elective cesarean section with a transverse incision were recruited for this study (Fig. 1). Patients who had a gestational age of 37 to 40 weeks and singleton pregnancy, voluntarily receiving intravenous patientcontrolled intravenous analgesia (PCIA) treatment, and classified as having ASA physical status scale I-II were eligible for participation. The reasons for an elective cesarean section in a primipara included the patient's own choice, preoperative complications including malpresentation (breech and transverse positions and compound presentation), placenta previa, uterine inertia, gestational diabetes, chronic or gestational hypertension, and preeclampsia. For the multiparas, the indication for a cesarean section was a previously scarred uterus. Only those who were undergoing their first repeat cesarean deliveries were included. Exclusion criteria included a history of chronic pain disorder, recent or chronic opioid use, substance abuse, heavy smoking (> 30 pack-years) [19] or alcohol dependence, absolute or relative contraindication to subarachnoid space block anesthesia, history of prior pelvic or abdominal surgery, or severe pregnancy complications, such as heart disease, brain disease, liver disease and kidney disease, that were life-threatening and required emergency treatment prior to the cesarean section.

\section{Anesthesia and Analgesia Management}

Cardiac rhythm via electrocardiography, mean arterial pressure, and pulse oxygen saturation were monitored after the patients entered the operating room. Standardized anesthesia was administered by an experienced anesthetist, and the operations were conducted by a single surgical team using the same standardized technique. Spinal anesthesia, via a subarachnoid space block at the L3-4 interspace, was administered using $0.66 \%$ ropivacaine $(20 \mathrm{mg})$.

After the fetal section and once daily after the surgery, oxytocin (20 IU in $500 \mathrm{~mL}$ of saline) was routinely administered while the patient was admitted to the obstetrics ward. PCIA was started immediately after surgery with a mixture of hydromorphone $(0.2 \mathrm{mg} / \mathrm{kg})$, flurbiprofen $(4 \mathrm{mg} / \mathrm{kg})$, and $0.9 \%$ normal saline at a dose volume of $200 \mathrm{~mL}$, using a controlled infusion pump. The pump was programmed to a loading dose of $2 \mathrm{~mL}$, background infusion rate of $2.0 \mathrm{~mL} / \mathrm{h}$, and PCIA dose of $1 \mathrm{~mL}$, with a lockout period of $15 \mathrm{~min}$. For the prevention of the postoperative nausea and vomiting, $3 \mathrm{mg}$ of droperidol was administered at the outset of PCIA. 


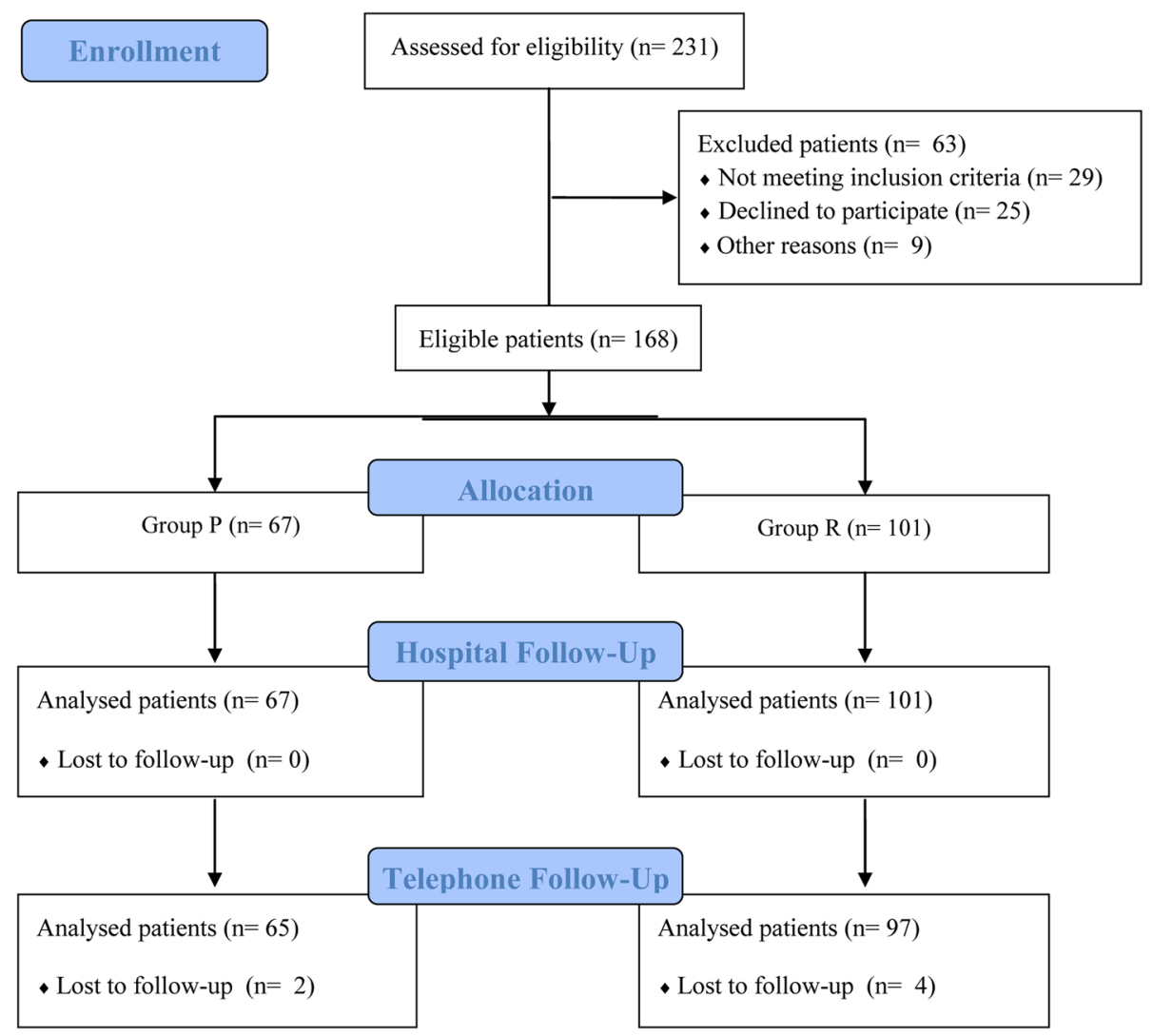

Fig. 1 The flow diagram of the study

Patients were monitored for $6 \mathrm{~h}$ in the postanesthesia care unit of the obstetrics ward after surgery. When pain was treated inadequately, the patients were administered additional pain treatment with tramadol $50 \mathrm{mg}$ in a timely manner.

\section{Outcome Measurements}

Standardized training for follow-up assessment was performed for all included investigators. A pain visual analogue scale (VAS score; $0-100$, where 0 is defined as no pain and 100 as maximum pain) was used to evaluate postoperative pain at $4,8,12,24$, and $48 \mathrm{~h}$. The primary outcome was the incidence of inadequate analgesia (defined as a pain VAS score $\geq 40$ ) [20] during the postoperative $48 \mathrm{~h}$. Pain caused by abdominal incision at rest and during mobilization (during coughing) was assessed using the VAS. Visceral pain was also assessed using the VAS. For visceral pain, the subjects were asked to report the pain induced by uterine contractions and were informed that the visceral pain could be enhanced when oxytocin was given. The duration of pain according to the patient's self-reported time and PCIA consumption for $48 \mathrm{~h}$ after surgery were recorded.

Assessment with the hospital anxiety and depression scale (HADS) before the operation was performed in all patients. The HADS includes 14 assessments, including the symptoms of anxiety and depression (seven items scored 0 to 3 in each subscale, yielding a range of $0-21$ ) with subscale scores of 8 indicating possible anxiety or depression [21, 22]. The intraoperative amount of blood loss, neonatal Apgar score, weight and height of the newborn, and surgery time were recorded. The Ramsay sedation score, respiratory rate, pulse oxygen saturation, systolic pressure, diastolic pressure, and heart rate were recorded before surgery and during the postoperative 48 h. Early walking time (determined by the time point when patients could ambulate) was also recorded. The sleep quality (rated as good or poor) on the day of and 1 day after surgery was evaluated. Postoperative adverse events including nausea, vomiting, and pruritus were also noted. Additionally, the patients' duration of hospital stay was recorded.

The results of routine blood examinations before and $24 \mathrm{~h}$ after the surgery were retrospectively collected for all patients. The leukocyte and neutrophil counts were analyzed. At 1 week and 4 weeks after surgery, patients were interviewed by telephone and asked the following questions from a standardized questionnaire: Was there an existing pain? Was the location of pain at the incision, viscera, both, or none? Was sleep affected? Were 
they able to perform the activities of daily life with full autonomy, partial dependency, or absolute dependence?

\section{Sample size determination}

The sample size was calculated according to the design of chi-square test for four-fold table data in a cohort study. Since previous studies reported the incidence of moderate to severe pain under postoperative analgesia for primipara as approximately $50 \%[4,5]$, the current study hypothesized that the relative risk (RR) value for multiparas was 1.5 compared to that for primiparas. The anticipated incidence for multiparas was $75 \%$. Therefore, based on a significance level of 0.05 , power of 0.9 , and an estimated ratio between the number of multiparas and primiparas of 1.5 , according to the retrospective analysis based on the data from our hospital Electronic Medical Records System of the past 1 year, and considering about 3\% loss of follow-up, the total required minimum sample size was determined to be 168 individuals using the sample size calculation software PASS, version 11.0 (NCSS, Kayesville, UT).

\section{Statistical Analysis}

Statistical analysis was performed using SPSS for Windows version 19.0 (SPSS Inc., Chicago, IL). A two-tailed $P$-value less than 0.05 was considered statistically significant. The mean \pm standard deviation (SD), median (interquartile range), and number (frequency) were used to summarize the variables. The patients who were scheduled to undergo a primary cesarean section were designated as group P in the final analysis, while the patients scheduled to undergo repeat cesarean section were designated as group $R$. The primary outcomes (postoperative inadequate analgesia on incision or visceral pain) were respectively described and analyzed. Logistic regression analysis using enter model was performed to evaluate the role of group $\mathrm{P}$ or group $\mathrm{R}$ in the prediction of postoperative inadequate analgesia. The presence of postoperative inadequate analgesia on incisional and visceral pain was considered as the outcome variable. BMI, age, gestational age, surgery time, preoperative complications (yes/no), depression (yes/no), and anxiety (yes/no) were also considered in the model. Odds ratios (OR) with $95 \%$ confidence intervals (CIs) were determined based on the logistic regression analysis.

An independent-sample t test was used to compare the differences in demographic and preoperative data between group P and R. Due to abnormal distribution, HAD scale, incision pain VAS at rest, and visceral pain VAS were compared using a Mann-Whitney U test. Propensity score matching (PSM) analysis was performed using STATA version 12 (Stata Corp, College Station, TX). Group P and group $\mathrm{R}$ were matched by propensity scores, and factors used to generate the propensity scores were those preoperative factors which had significant difference between the two groups. These factors included age, gestational age, and preoperative complications. Patients were matched in a 1:1 ratio without replacement. The caliper was defined as 0.2. The absolute standardized difference was calculated, and the absolute standardized difference less than $10 \%$ was considered to support the assumption of balance between the two groups. Then, other postoperative outcomes including the start time to feel pain, early walking time, hospital stays and PCIA administration were compared between groups $\mathrm{P}$ and $\mathrm{R}$.

Differences in the incidence of postoperative inadequate analgesia, sleep quality, adverse events, and longterm pain status between the two groups were analyzed using Pearson's chi-squared test. Furthermore, RR values and $95 \% \mathrm{CI}$ for the probability of the occurrence of inadequate analgesia on incision pain and visceral pain during the postoperative 48 -h follow-up were calculated, as well as the postoperative pain status at 1 and 4 weeks. Subgroup analysis according to age group $(\leq 30$ years or $>$ 30 years) was performed. Two-way repeated analysis of variance (ANOVA) with post hoc LSD testing was used to compare the preoperative and postoperative systolic pressure, diastolic pressure, heart rate, respiratory rate, and leukocyte and neutrophil counts between the two groups.

\section{Results}

\section{General results}

Among the 67 primiparas who were scheduled to undergo cesarean section, 54 underwent the procedure due to preoperative complications (maternal or fetal factors) and 13 due to social factors. For the 101 multiparas, all underwent the procedure due to the history of a previous cesarean section. Fifty-four also had accompanying preoperative complications. As shown in Fig. 1, all patients completed the postoperative 48-h follow-up. However, six patients (two in group $\mathrm{P}$ and 4 in group $\mathrm{R}, P=0.739$ ) could not complete the study either because they could not be contacted or they withdrew from the study. The demographic and preoperative data of all patients are shown in Table 1. The results showed that the incidence of severe bleeding $(\geq 500 \mathrm{~mL}$ ) was $5.9 \%(6 / 101)$ in group $\mathrm{R}$ and was $7.5 \%$ (5/ 67) in group $P$ and that there was no difference between the two groups $(P=0.696)$.

\section{Logistic regression analysis}

Enter logistic regression models were applied to explore the possible predictors for postoperative inadequate analgesia on incisional pain and visceral pain. For the model of incisional pain, the statistical test for the overall model was significant $(P=0.001)$, and the predicted accuracy rate based on this model was $80.8 \%$, while the overall model was not significant $(P=0.589)$ for visceral pain. As summarized in Table 2, patient group and 
Table 1 Demographic, preoperative and intraoperative data

\begin{tabular}{llll}
\hline & Group P $(n=67)$ & Group R $(n=101)$ & Statistics \\
\hline Age (year) & $29.5 \pm 3.9$ & $31.3 \pm 3.4$ & $t=3.112, P=0.002$ \\
Age group $(>30)$ & $20(29.9 \%)$ & $57(56.4 \%)$ & $X^{2}=11.467, P=0.001$ \\
BMI $\left(\mathrm{kg} / \mathrm{m}^{2}\right)$ & $26.7 \pm 1.9$ & $26.9 \pm 1.9$ & $t=0.820, P=0.415$ \\
Gestational age (week) & $38.9 \pm 0.9$ & $38.4 \pm 0.6$ & $t=103, P<0.001$ \\
Preoperative complications & $54(80.6 \%)$ & $54(53.5 \%)$ & $t=12.912, P<0.001$ \\
HADS-A(score) & $2(0,5)$ & $1(0,4)$ & $U=0.887, P=0.375$ \\
HADS-D (score) & $0(0,2)$ & $0(0,2)$ & $U=0.129, P=0.897$ \\
Surgery duration (min) & $62.1 \pm 15.3$ & $71.1 \pm 16.2$ & $t=3.782, P<0.001$ \\
Weight of newborn (g) & $3278 \pm 481$ & $3443 \pm 1074$ & $t=1.185, P=0.238$ \\
Height of newborn $(\mathrm{cm})$ & $49.7 \pm 2.1$ & $49.9 \pm 1.7$ & $t=0.820, P=0.505$ \\
Blood loss (mL) & $286 \pm 94$ & $306 \pm 92$ & $t=0.668, P=0.889$ \\
\hline
\end{tabular}

Group $\mathrm{P}$ and $\mathrm{R}$ mean patients who received primary and repeated cesarean delivery, respectively; Data were presented as Means $\pm \mathrm{SD}$, median (interquartile range) or as numbers (percentage); $B M I=$ Body mass index; $H A D S-A=$ Hospital anxiety scale; $H A D S-D=$ Hospital depression scale

preoperative complications were identified as significant factors for inadequate analgesia on incision pain. This showed that patients in group $\mathrm{P}$ or with accompanying preoperative complications would have higher odds of inadequate pain control.

\section{Postoperative Data}

The distribution of pain VAS is shown in Fig. 2. The incidence of inadequate postoperative analgesia on incision or visceral pain at different times is shown in Fig. 3. In total, $24.4 \%(41 / 168)$ of patients were found to have inadequate treatment for their incision pain (Fig. 3a). The total incidence of inadequate analgesia on incision pain in group $\mathrm{P}$ was significantly higher than that in group $R$, and the $R R$ for multiparas to experience inadequate analgesia on incision pain was 0.42 (95\% CI: 0.25 to $0.74 ; P=0.001$ ) compared to primiparas. As shown in Fig. 3b, the total incidence of inadequate analgesia on visceral pain in group $\mathrm{P}$ was lower than that in group $\mathrm{R}$, and the RR for patients in group $\mathrm{R}$ to experience inadequate analgesia on visceral pain was 1.75 ( $95 \%$ CI: 0.82 to $3.70 ; P=0.078$ ) compared to that for patients in group $P$. In addition, no significant difference was found in the total combined incidence of inadequate analgesia between groups P and R (Fig. 3c).

The results of subgroup analysis showed that group $\mathrm{R}$ was associated with a lower incidence of inadequate control on

Table 2 Logistic regression analysis of inadequate analgesia on incision pain and visceral

\begin{tabular}{|c|c|c|c|c|c|}
\hline Outcome & Predictors & Wals & $P$ value & OR & $95 \% \mathrm{Cl}$ \\
\hline \multirow[t]{8}{*}{ Inadequate analgesia on incision pain } & Age (year) & 0.543 & 0.461 & 1.043 & 0.932 to 1.169 \\
\hline & $\mathrm{BMI}\left(\mathrm{kg} / \mathrm{m}^{2}\right)$ & 0.193 & 0.660 & 1.048 & 0.850 to 1.293 \\
\hline & Gestational age (week) & 0.035 & 0.853 & 1.048 & 0.637 to 1.727 \\
\hline & Preoperative complications (yes/no) & 4.721 & 0.030 & 0.365 & 0.147 to 0.906 \\
\hline & Surgery duration (min) & 3.610 & 0.057 & 1.000 & 0.999 to 1.000 \\
\hline & Patient group(P/R) & 10.790 & 0.001 & 0.191 & 0.071 to 0.513 \\
\hline & Anxiety (yes/no) & 0.000 & 0.999 & 0.000 & NA \\
\hline & Depression (yes/no) & 0.000 & 0.999 & 0.000 & NA \\
\hline \multirow[t]{8}{*}{ Inadequate analgesia on visceral pain } & Age & 3.463 & 0.063 & 0.897 & 0.801 to 1.006 \\
\hline & BMl & 0.002 & 0.968 & 1.005 & 0.804 to 1.256 \\
\hline & Gestational age (week) & 0.175 & 0.675 & 0.885 & 0.498 to 1.570 \\
\hline & Preoperative complications (yes/no) & 0.277 & 0.599 & 1.273 & 0.519 to 3.124 \\
\hline & Surgery duration (min) & 0.586 & 0.444 & 1.000 & 0.999 to 1.000 \\
\hline & Patient group(P/R) & 0.599 & 0.439 & 1.515 & 0.529 to 4.340 \\
\hline & Anxiety (yes/no) & 0.133 & 0.715 & 1. 462 & 0.190 to 11.219 \\
\hline & Depression (yes/no) & 0.423 & 0.515 & 0.403 & 0.026 to 6.228 \\
\hline
\end{tabular}




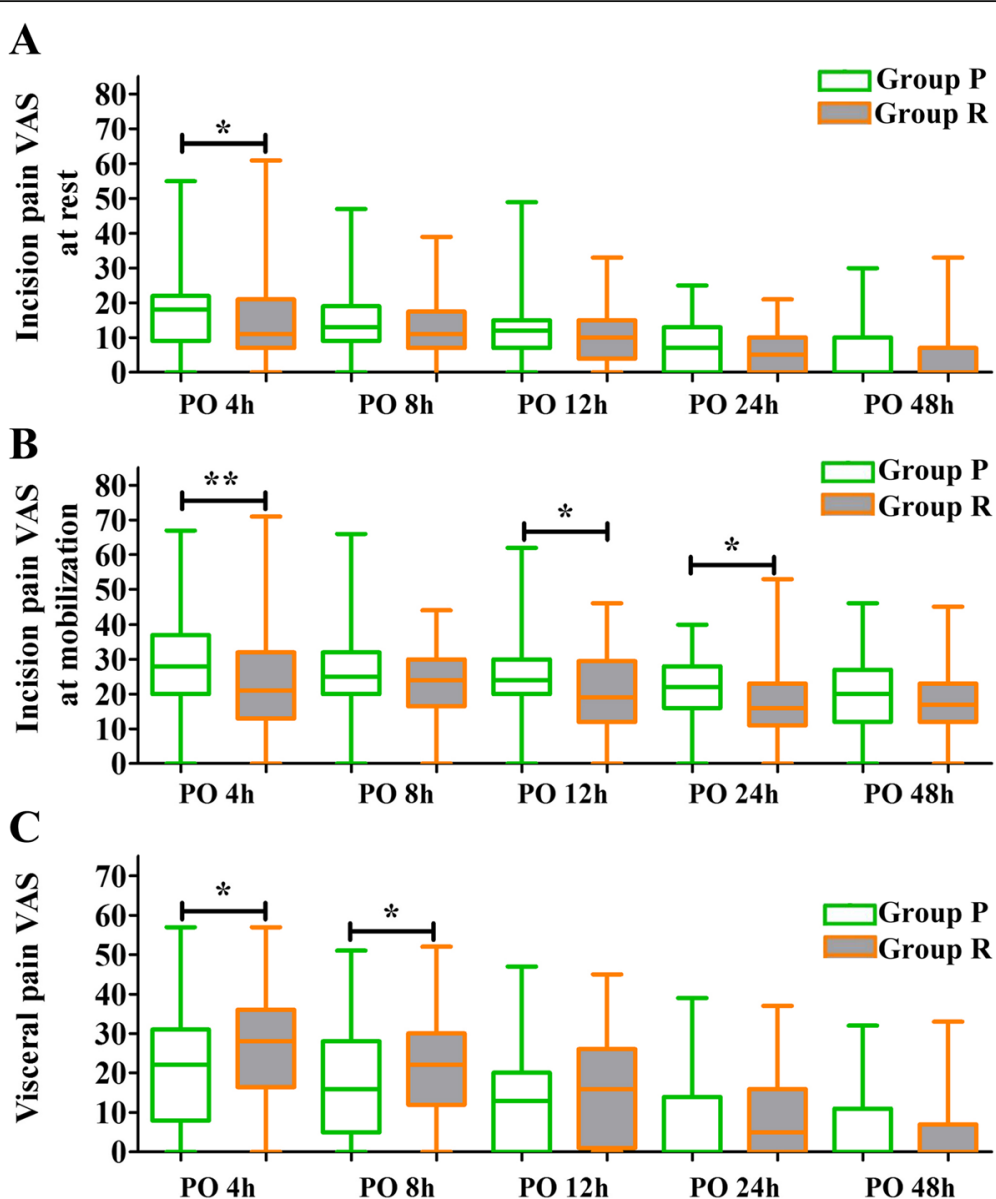

Fig. 2 The distribution of postoperative incision pain VAS at rest (a) incision pain VAS at mobilization (b) and visceral pain VAS (c) at different time points. Means of groups $P$ and $R$ patients who received primary and repeated cesarean section, respectively; VAS $=$ visual analogue scale; $\mathrm{PO}=$ postoperative; ${ }^{*} P<0.05$; ${ }^{*} P<0.01$

incision pain in both age groups $(\leq 30$ and $>30$ years; $R R$, 0.47 [0.23 to 0.98$], P=0.033$ and 0.40 [0.17 to 0.96$], P=$ 0.042 , respectively, Table 3). Group R was associated with a higher incidence of inadequate control on viscera pain in the age group $\leq 30$ years (RR, 3.56 [1.05 to 12.04], $P=0.025$ ).

After propensity score matching according to preoperative factors, including age, gestational age, and preoperative complications, no significant differences remained between the two groups, and a total of 45 pairs of subjects were included for comparison of other postoperative outcomes (Table 4). As shown in Table 5, the pain VAS score at different time points were listed, and the distributions were similar to that in the non-matched cohort. Furthermore, the RR in multiparas for inadequate analgesia on incision pain was 0.35 (95\% CI: 0.15 to $0.79 ; P=0.007$ ) compared to primiparas in this matched cohort. There was no significant difference in the incidence of inadequate analgesia on visceral pain between the two groups $(P>0.05)$. In addition, there was no significant difference in the incidence of adverse effects between the two groups. No respiratory depression, excessive sedation, or agitation was found in the present study. In addition, no significant difference was found in the time elapsed prior to the onset of pain, early waking time, sleep quality, and PCIA administration between the two groups. The results showed the mean hospital stay for primiparas was longer than that for multiparas.

\section{Changes of serum leukocyte count and neutrophil count}

Two-way repeated ANOVA for leukocyte count showed a group effect $(P=0.004)$, time effect $(P<0.001)$, and group and time interaction effect $(P=0.024)$. For the neutrophil count, the group effect $(P=0.012)$ and time effect $(P<0.001)$ were significant, while group and time interaction effects were not significant $(P=0.023)$. As shown in Fig. 4, there was no difference in the absolute leukocyte $\left(9.03 \pm 2.19 \times 10^{9} / \mathrm{L}\right.$ vs. $8.38 \pm 2.57 \times 10^{9} / \mathrm{L}$, $P=0.202)$ and neutrophil $\left(6.81 \pm 2.02 \times 10^{9} / \mathrm{L}\right.$ vs. $6.41 \pm$ $\left.2.39 \times 10^{9} / \mathrm{L}, P=0.388\right)$ counts between the different groups before the surgery, while both leukocyte $\left(10.76 \pm 2.40 \times 10^{9} / \mathrm{L}\right.$ vs. $\left.8.97 \pm 1.81 \times 10^{9} / \mathrm{L}, P<0.001\right)$ and neutrophil $\left(8.33 \pm 2.31 \times 10^{9} / \mathrm{L}\right.$ vs. $6.78 \pm 1.61 \times 10^{9} /$ 

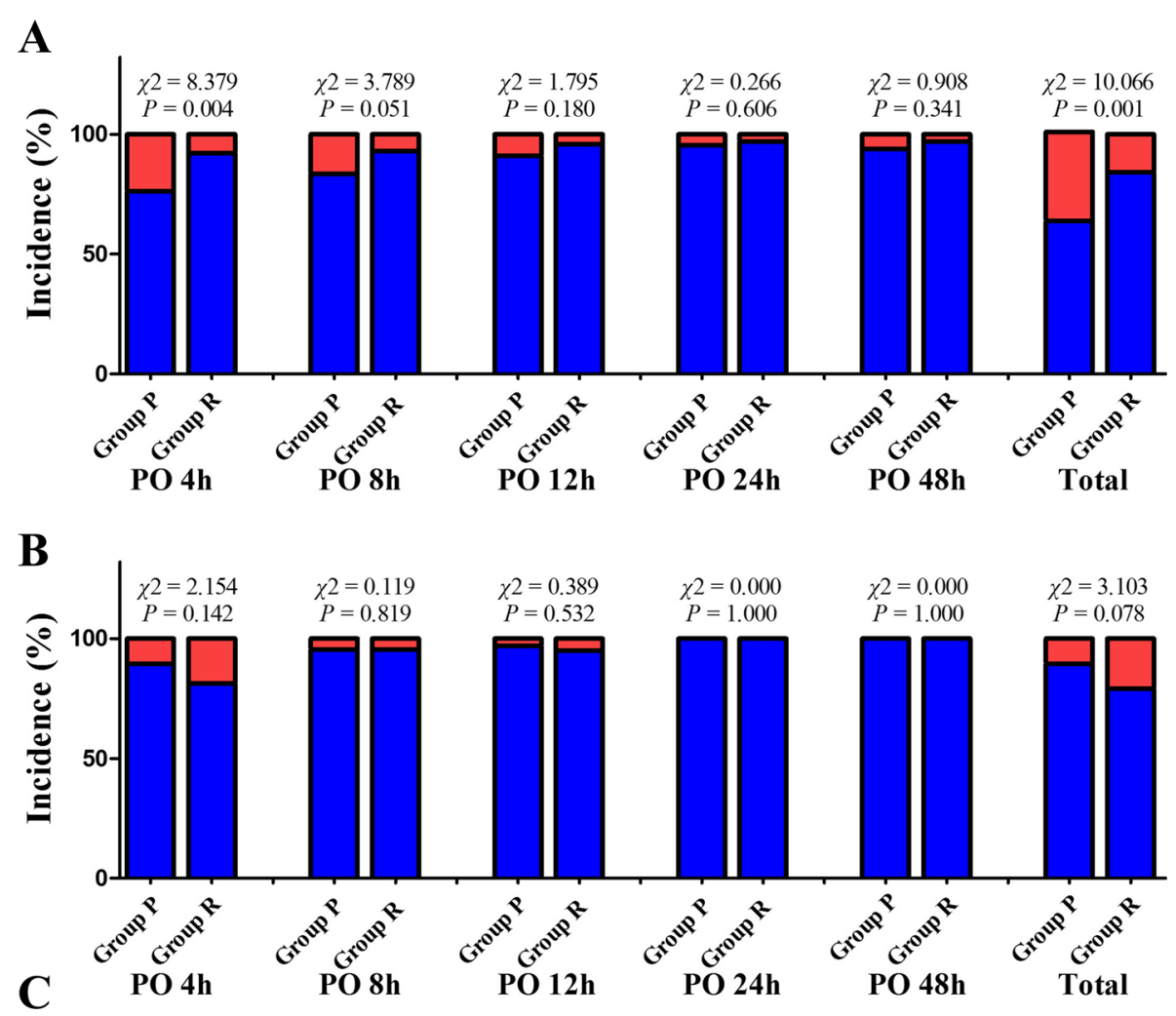

PO 24h

PO 48h

Total

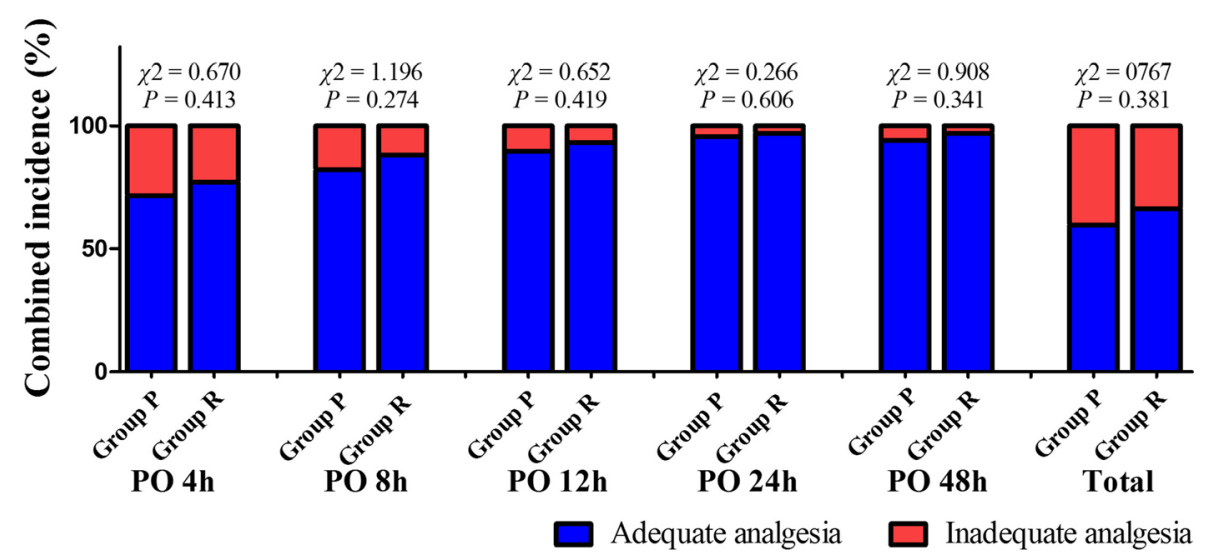

Fig. 3 The incidence of postoperative inadequate treatment on incision pain (a), visceral pain (b) and the combined incidence (c) Groups $P$ and $\mathrm{R}$ represent patients who underwent primary and repeated cesarean sections, respectively; $\mathrm{VAS}=$ visual analogue scale; $\mathrm{PO}=$ postoperative.

Table 3 Subgroup analysis for different age groups

\begin{tabular}{lllll}
\hline Age group & Outcomes & Group P & Group R & Statistics \\
\hline$\leq 30$ years & Inadequate control on incision pain & $18(38.3 \%)$ & $8(18.2 \%)$ & $x 2=4.506, P=0.033$ \\
& Inadequate control on viscera pain & $3(6.4 \%)$ & $10(22.7 \%)$ & $X 2=4.958, P=0.025$ \\
& Inadequate control on both incision and viscera pain & $18(38.3 \%)$ & $16(36.4 \%)$ & $X 2=0.036, P=0.849$ \\
$>30$ years & Inadequate control on incision pain & $7(35.0 \%)$ & $8(14.0 \%)$ & $x 2=4.149, P=0.042$ \\
& Inadequate control on viscera pain & $5(25.0 \%)$ & $11(19.3 \%)$ & $X 2=0.292, P=0.588$ \\
& Inadequate control on both incision and viscera pain & $9(45.0 \%)$ & $18(31.6 \%)$ & $X 2=1.171, P=0.279$ \\
\hline
\end{tabular}

Group P and R mean patients who received primary and repeated cesarean delivery, respectively; Data were presented as numbers (percentage) 
Table 4 The postoperative short-term outcomes in different groups after propensity score matching

\begin{tabular}{llll}
\hline Outcomes & Group P $(n=45)$ & Group R $(n=45)$ & Statistics \\
\hline Age (year) & $30.3 \pm 4.3$ & $30.8 \pm 3.4$ & $t=0.555, P=0.580$ \\
Gestational age (week) & $38.6 \pm 1.0$ & $38.5 \pm 0.7$ & $t=0.569, P=0.571$ \\
Preoperative complications & $5(11.1 \%)$ & $3(6.7 \%)$ & $X 2=0.548, P=0.458$ \\
Time to feel pain (hour) & $3(2,6)$ & $4(2,7)$ & $U=0.858, P=0.391$ \\
Early walking time (hour) & $28.9 \pm 8.8$ & $28.5 \pm 9.6$ & $t=0.213, P=0.832$ \\
Nausea or vomiting & $3(6.7 \%)$ & $4(8.9 \%)$ & $X 2=0.155, P=0.693$ \\
Pruritus & $2(4.5 \%)$ & $3(6.7 \%)$ & $x 2=0.212, P=0.645$ \\
Sleep quality PO Od (poor) & $16(35.6 \%)$ & $13(28.9 \%)$ & $X 2=0.457, P=0.498$ \\
Sleep quality PO 1d (poor) & $5(11.1 \%)$ & $3(6.7 \%)$ & $x 2=0.548, P=0.458$ \\
PCIA consumption (mL) & $111.1 \pm 36.0$ & $110.9 \pm 37.3$ & $t=0.026, P=0.979$ \\
Hospital stays (day) & $3.5 \pm 1.1$ & $3.0 \pm 0.8$ & $t=2.513, P=0.014$ \\
\hline
\end{tabular}

Group $\mathrm{P}$ and $\mathrm{R}$ mean patients who received primary and repeated cesarean delivery, respectively; Data were presented as means $\pm \mathrm{SD}$, median (interquartile range) or as numbers (percentage); $P O=$ Postoperative; $P C I A=$ Patient controlled intravenous analgesia

$\mathrm{L}, P<0.001)$ counts at $24 \mathrm{~h}$ after the surgery in group $\mathrm{P}$ were significantly higher than that in group $R$.

\section{Long-term follow-up}

As shown in Table 6, no significant difference in pain status was found between the two groups 1 week after surgery. The results showed that at 4 weeks after surgery, the incidence of existing pain in group $\mathrm{P}$ was significantly higher than that in group $\mathrm{R}$.
In additional, a significant difference was noted in the location of pain between patients in group $\mathrm{P}$ and group $\mathrm{R}$.

\section{Discussion}

Our results show that the total incidence of inadequate postoperative pain control was $36.3 \%$ using PCIA combined with hydromorphone and flurbiprofen, which was demonstrated as an effective combination for postoperative pain control [23]. One previous prospective cohort

Table 5 The patients' postoperative pain in different groups after propensity score matching

\begin{tabular}{|c|c|c|c|}
\hline Outcomes & Group P $(n=45)$ & Group $\mathrm{R}(n=45)$ & Statistics \\
\hline Rest incision pain VAS at PO $4 \mathrm{~h}$ & $18(11,20)$ & $11(7,16)$ & $U=2.508, P=0.012$ \\
\hline Moving incision pain $\mathrm{VAS}$ at $\mathrm{PO} 4 \mathrm{~h}$ & $29(21,39)$ & $23(13,30)$ & $U=2.705, P=0.007$ \\
\hline Visceral pain VAS at PO $4 \mathrm{~h}$ & $22(6,32)$ & $27(17,36)$ & $U=1.690, P=0.091$ \\
\hline Rest incision pain VAS at PO $8 \mathrm{~h}$ & $13(9,19)$ & $9(4,13)$ & $U=2.423, P=0.015$ \\
\hline Moving incision pain VAS at PO $8 \mathrm{~h}$ & $25(21,34)$ & $22(12,29)$ & $U=1.922, P=0.055$ \\
\hline Visceral pain VAS at PO $8 \mathrm{~h}$ & $21(8,28)$ & $20(11,30)$ & $U=0.342, P=0.732$ \\
\hline Rest incision pain VAS at PO $12 \mathrm{~h}$ & $12(6,15)$ & $9(3,12)$ & $U=1.973, P=0.048$ \\
\hline Moving incision pain VAS at PO $12 \mathrm{~h}$ & $24(21,32)$ & $15(10,26)$ & $U=3.198, P=0.001$ \\
\hline Visceral pain VAS at PO $12 \mathrm{~h}$ & $13(0,25)$ & $11(0,24)$ & $U=0.470, P=0.638$ \\
\hline Rest incision pain VAS at PO $24 \mathrm{~h}$ & $6(0,13)$ & $4(0,6)$ & $U=1.482, P=0.138$ \\
\hline Moving incision pain VAS at PO $24 \mathrm{~h}$ & $22(17,29)$ & $14(9,20)$ & $U=3.408, P=0.001$ \\
\hline Visceral pain VAS at PO $24 \mathrm{~h}$ & $0(0,13)$ & $5(0,15)$ & $U=0.373, P=0.709$ \\
\hline Rest incision pain VAS at PO $48 \mathrm{~h}$ & $0(0,8)$ & $0(0,4)$ & $U=1.043, P=0.297$ \\
\hline Moving incision pain VAS at PO $48 \mathrm{~h}$ & $20(12,27)$ & $14(10,20)$ & $U=1.804, P=0.071$ \\
\hline Visceral pain VAS at PO $48 \mathrm{~h}$ & $0(0,8)$ & $0(0,5)$ & $U=0.096, P=0.924$ \\
\hline Inadequate analgesia on incision pain & $17(37.8 \%)$ & $6(13.0 \%)$ & $X 2=7.368, P=0.007$ \\
\hline Inadequate analgesia on visceral pain & $7(15.6 \%)$ & $9(19.6 \%)$ & $x^{2}=0.252, P=0.615$ \\
\hline
\end{tabular}

Group P and R mean patients who received primary and repeated cesarean delivery, respectively; Data were presented as median (interquartile range) or as numbers (percentage); $P O=$ Postoperative; $V A S=$ Visual analogue scale 

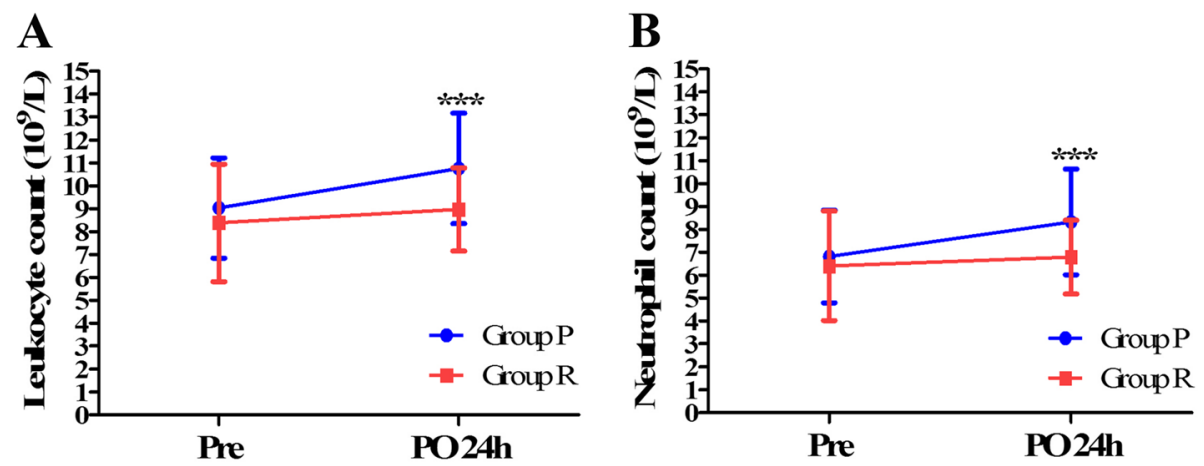

Fig. 4 Changes in leukocyte count (a) and neutrophil count (b) before and after surgery. Means of groups $P$ and R patients who underwent primary and repeated cesarean sections, respectively; Pre = preoperative; $P O=$ postoperative; ${ }^{* * *}$ compared to group $R, P<0.001$.

study [4] demonstrated that postoperative pain after a cesarean section reached 6 (interquartile range: 4 to 8 ), and the incidence of moderate to severe pain or requirement of extra analgesia was reported to range from 40 to $60 \%[5,6]$. Therefore, the analgesia strategy in this study might be effective for postoperative pain control. Nevertheless, the incidence of $36.3 \%$ remains relatively high, and more effective analgesia strategies should be explored in the future.

As we know, a high proportion of female patients are scheduled to undergo secondary cesarean section because of a previous cesarean section. In the United States, a repeat cesarean section due to a previous uterine scar contributed to more than $30 \%$ of all cesarean sections [24, 25]. Severe adhesions induced by previous surgery were often inevitable and thus, would cause higher operative difficulties [26, 27]. In this study, surgery duration in group $\mathrm{R}$ was significantly longer than that in group $\mathrm{P}$, which is also indicative of higher operative difficulties in patients with repeat cesarean sections. In addition, previous surgery history might increase the patients' pain sensitivity $[28,29]$. Therefore, based on the above information, it was speculated that multiparas might experience more postoperative pain than primiparas.

For patients undergoing cesarean section, oxytocin, which can induce contraction pain, was routinely used to reduce intraoperative and postoperative hemorrhage [30,31]. Thus, postoperative visceral pain induced by uterine contraction must frustrate the patients and should not be ignored. Although numerous previous studies have focused on the improvement of postoperative analgesia for cesarean section [32-35], many of these studies did not differentiate incision pain from visceral pain. However, a previous study found that the analgesic effects of the same analgesics on incision

Table 6 The long-term postoperative outcomes in different groups after propensity score matching

\begin{tabular}{|c|c|c|c|c|}
\hline $\begin{array}{l}\text { Time } \\
\text { point }\end{array}$ & Outcomes & Group P $(n=45)$ & Group R $(n=45)$ & Statistics \\
\hline \multirow[t]{4}{*}{ PO 1 week } & Experiencing pain & $38(84.4 \%)$ & $35(77.7 \%)$ & $\begin{array}{l}X 2=0.653 \\
P=0.419\end{array}$ \\
\hline & location of pain (abdominal incision/viscera /both) & $\begin{array}{l}26(57.8 \%) / 5(11.1 \%) / 3 \\
(6.7 \%)\end{array}$ & $\begin{array}{l}26(57.8 \%) / 3(6.7 \%) / 0 \\
(0.0 \%)\end{array}$ & $\begin{array}{l}X 2=4.426 \\
P=0.219\end{array}$ \\
\hline & Affect sleep & $14(31.1 \%)$ & $10(22.2 \%)$ & $\begin{array}{l}X 2=0.909 \\
P=0.340\end{array}$ \\
\hline & Ability of daily life (partial dependency/fully autonomy) & $19(42.2 \%) / 26(57.8 \%)$ & $18(40.0 \%) / 27(60.0 \%)$ & $\begin{array}{l}X 2=0.046 \\
P=0.830\end{array}$ \\
\hline \multirow[t]{4}{*}{ PO 4 week } & Experiencing pain & $28(62.2 \%)$ & $17(37.7 \%)$ & $\begin{array}{l}X 2=6.403 \\
P=0.011\end{array}$ \\
\hline & location of pain (abdominal incision/ viscera/both) & $\begin{array}{l}18(40.0 \%) / 7(15.6 \%) / 1 \\
(2.2 \%)\end{array}$ & $8(17.8 \%) / 4(8.9 \%) / 0(0 \%)$ & $\begin{array}{l}X 2=9.434 \\
P=0.024\end{array}$ \\
\hline & Affect sleep & $8(17.8 \%)$ & $4(8.9 \%)$ & $\begin{array}{l}X 2=1.538 \\
P=0.215\end{array}$ \\
\hline & $\begin{array}{l}\text { Ability of daily life (partial dependency/ fully } \\
\text { autonomy) }\end{array}$ & $45(100 \%) / 0(0 \%)$ & $45(100 \%) / 0(0 \%)$ & $\begin{array}{l}X 2=0.000 \\
P=1.000\end{array}$ \\
\hline
\end{tabular}

Group $\mathrm{P}$ and $\mathrm{R}$ mean patients who received primary and repeated cesarean delivery, respectively; Data were presented as numbers (percentage); $P O=$ Postoperative 
and uterine cramping pain varied [36]. Therefore, postoperative abdominal incision and visceral pain were evaluated in this study.

One previous study demonstrated that compared to primiparous women, the analgesic effect on post-cesarean uterine cramping pain is less in multiparous women [37]. The current results also showed that the incidence of inadequate treatment on visceral pain in group $\mathrm{R}$ was higher than that in group $\mathrm{P}$, with the RR for multipara being 3.56 ( $95 \%$ CI: 1.05 to 12.04 ) in the patients aged $\leq 30$ years. In addition, of all patients in the two groups, few were found to experience inadequate analgesia $8 \mathrm{~h}$ after the surgery, indicating that visceral pain might mainly appear at an early postoperative stage. Therefore, for the multipara, the focus should be on postoperative visceral pain at the early stage, especially for young patients.

In contrast, this study showed that multiparas were less likely to experience inadequate treatment on incision pain. The RR for multiparas was 0.42 (95\% CI: 0.25 to 0.74), and the mean incision pain VAS score in group $\mathrm{R}$ was significantly lower than that in group $\mathrm{P}$ at several time points, including 4,12 , and $24 \mathrm{~h}$ after surgery. Based on the results of the current study, several reasons might account for this phenomenon. First, as shown in the study, the rate of preoperative complications in group $\mathrm{P}$ was higher than that in group R ( $80.6 \%$ vs. $53.5 \%)$ and was identified as a significant risk factor for inadequate treatment on incision pain. Second, through retrospective analysis, we found that both the leukocyte count and neutrophil count were significantly increased $24 \mathrm{~h}$ post-operation compared to that prior to surgery, and these elevations were higher in group P than in group R. Previous studies $[38,39]$ have also reported that there was a significant difference between preoperative and postoperative leukocyte and neutrophil counts for patients undergoing cesarean deliveries. However, it remains unclear whether this difference varied between primiparas and multiparas after cesarean deliveries. Increases in white blood cell and neutrophil counts have been demonstrated to be positively associated with inflammatory responses in previous studies [40-42]. Therefore, this indicated that different physiological responses to surgery or analgesia might exist between multiparas and primiparas. For primiparas, an effective analgesia strategy, e.g., combination of perioperative anti-inflammatory agents on incision pain should be considered.

In summary, because of the difference between postoperative control on visceral and incision pain, there was no significant difference in the combined incidence of inadequate analgesia on both types of pain between patients in groups $\mathrm{P}$ and R. Regarding the other postoperative outcomes during the hospital stay, no significant difference was found in the incidence of adverse events, time to feel pain, early walking time, sleep quality, and PCIA administration between the two groups. However, we found that the mean hospital stay for primiparas was longer than that for multiparas. This indicated that primiparas might need more care after cesarean section. Furthermore, the current study demonstrated that primiparas might experience a longer duration of pain, because higher incidences of existing pain and affected sleep were found in group $P$ than in group $R 4$ weeks after surgery. This might be due to the higher incidence of inadequate incision pain control in patients of group $\mathrm{P}$, because a previous study has identified inadequately controlled acute postoperative pain as a risk factor for the development of chronic pain post-operation [43].

Several limitations should be noted in the study. First, the study only included Chinese women from urban areas; thus, race and socio-economic status should be considered when interpreting the current results [44, 45]. Second, although a significant difference in postoperative pain status was found between primiparas and multiparas, the current sample size was relatively small. Third, in the current study, all multiparas were undergoing secondary surgery; thus, the differences for those who underwent two or more cesarean deliveries were not known. Thus, to address these potential limitations, a multicenter study with a larger sample size might be needed, and more studies including other populations should be performed in the future.

\section{Conclusion}

Multiparas under 30 years of age may be more prone to experiencing moderate to severe visceral pain under PCIA with opioids during the first $48 \mathrm{~h}$ after surgery compared to primiparas; however, primiparas have a higher incidence of inadequate treatment on incision pain and possibly a higher incidence of existing pain 4 weeks after surgery. Based on the results of the current study, individual differences between primipara and multipara should be considered in postoperative analgesia in the future.

\section{Abbreviations \\ ANOVA: analysis of variance; Cl: confidence intervals; HADS: hospital anxiety and depression scale; OR: Odds ratios; PCIA: patient-controlled intravenous} analgesia; RR: Relative Risk; SD: standard deviation; VAS: visual analogue scale

\section{Acknowledgements \\ Not Applicable.}

\section{Authors' Contributions}

Conceptualization, JP; Data curation, GY, JP, ZD, JL, and XT; Formal analysis, GD, GY, and HL; Funding acquisition, GD and $H L$; Investigation, ZD, JL, and $X T$; Supervision, HL; Writing original draft, GD and GY; Writing - review and editing, HL. All authors have read and approved the manuscript.

\section{Funding}

The study was supported by Clinical Research Projects of Second Affiliated Hospital of Army Medical University, PLA (No 2016D415, HL and No. 2016YLC10, GD) in design of the study and collection, analysis, and interpretation of data. 


\section{Availability of data and materials}

All data can be acquired from the corresponding author $(\mathrm{HL})$ by request.

\section{Ethics approval and consent to participate}

The study protocol was approved by the Institutional Ethics Committee of Xinqiao Hospital, Army Medical University. Written informed consent was obtained from all patients and the study was registered on ClinicalTrial.gov (ID: NCT03009955, December 30, 2016).

\section{Consent for publication}

Not Applicable.

\section{Competing interests}

The authors declare no competing interests.

\section{Received: 26 November 2018 Accepted: 30 September 2019} Published online: 22 October 2019

\section{References}

1. Martin JA, Hamilton BE, Osterman MJK. Births in the United States 2016. NCHS Data Brief. 2017;287:1-8.

2. Liang J, Mu Y, Li X, et al. Relaxation of the one child policy and trends in caesarean section rates and birth outcomes in China between 2012 and 2016: observational study of nearly seven million health facility births. BMJ. 2018:360:k817

3. Raja SN, Jensen TS. Predicting postoperative pain based on preoperative pain perception: are we doing better than the weatherman? Anesthesiology. 2010;112:1311-2.

4. Gerbershagen HJ, Aduckathil S, van Wijck AJ, Peelen LM, Kalkman CJ, Meissner W. Pain intensity on the first day after surgery: a prospective cohort study comparing 179 surgical procedures. Anesthesiology. 2013 118:934-44

5. Patel R, Carvalho JC, Downey K, Kanczuk M, Bernstein P, Siddiqui N. Intraperitoneal Instillation of Lidocaine Improves Postoperative Analgesia at Cesarean Delivery: A Randomized, Double-Blind, Placebo-Controlled Trial. Anesth Analg. 2017;124:554-9.

6. Ortner CM, Granot M, Richebe P, Cardoso M, Bollag L, Landau R. Preoperative scar hyperalgesia is associated with post-operative pain in women undergoing a repeat Caesarean delivery. Eur J Pain. 2013;17:111-23.

7. Eisenach JC, Pan PH, Smiley R, Lavand'Homme P, Landau R, Houle $T T$. Severity of acute pain after childbirth, but not type of delivery, predicts persistent pain and postpartum depression. Pain. 2008;140:87-94.

8. Lavand'Homme P. Chronic pain after vaginal and cesarean delivery: a reality questioning our daily practice of obstetric anesthesia. Int J Obstet Anesth. 2010;19:1-02.

9. Zeng Y, Hesketh T. The effects of China's universal two-child policy. Lancet 2016:388:1930-8

10. Wang $L, X u X$, Baker $P$, et al. Factors associated with intention to have caesarean delivery in pregnant women in China: a cross-sectional analysis. Lancet. 2016:388 Suppl 1:S2

11. Gasim T, Al JF, Rahman MS, Rahman J. Multiple repeat cesarean sections: operative difficulties, maternal complications and outcome. J Reprod Med. 2013:58:312-8.

12. Elbohoty AE, Gomaa MF, Abdelaleim M, Abd-El-Gawad M, Elmarakby M. Diathermy versus scalpel in transverse abdominal incision in women undergoing repeated cesarean section: A randomized controlled trial. J Obstet Gynaecol Res. 2015:41:1541-6.

13. Practice Guidelines for Obstetric Anesthesia. An Updated Report by the American Society of Anesthesiologists Task Force on Obstetric Anesthesia and the Society for Obstetric Anesthesia and Perinatology. Anesthesiology. 2016:124:270-300

14. Practice Bulletin No. 177: Obstetric Analgesia and Anesthesia. Obstert Gynecol. 2017;129:e73-e89.

15. Pan PH, Tonidandel AM, Aschenbrenner CA, Houle T, Harris LC, Eisenach JC. Predicting acute pain after cesarean delivery using three simple questions. Anesthesiology. 2013;118:1170-9.

16. Ip HY, Abrishami A, Peng PW, Wong J, Chung F. Predictors of postoperative pain and analgesic consumption: a qualitative systematic review. Anesthesiology. 2009;111:657-77.

17. von Elm E, Altman DG, Egger M, Pocock SJ, Gotzsche PC, Vandenbroucke JP. The Strengthening the Reporting of Observational Studies in
Epidemiology (STROBE) statement: guidelines for reporting observational studies. PLoS Med. 2007:4:e296.

18. Eisenach JC, Kheterpal S, Houle TT. Reporting of Observational Research in ANESTHESIOLOGY: The Importance of the Analysis Plan. Anesthesiology. 2016;124:998-1000.

19. Pietzak EJ, Mucksavage P, Guzzo TJ, Malkowicz SB. Heavy Cigarette Smoking and Aggressive Bladder Cancer at Initial Presentation. Urology. 2015;86:968-72.

20. Duan G, Xiang G, Zhang X, Yuan R, Zhan H, Qi D. A single-nucleotide polymorphism in SCN9A may decrease postoperative pain sensitivity in the general population. Anesthesiology. 2013;118:436-42.

21. de Miranda S, Pochard F, Chaize M, et al. Postintensive care unit psychological burden in patients with chronic obstructive pulmonary disease and informal caregivers: A multicenter study. Crit Care Med. 2011;39:112-8.

22. Zigmond AS, Snaith RP. The hospital anxiety and depression scale. Acta Psychiatr Scand. 1983;67:361-70.

23. Oh E, Ahn HJ, Sim WS, Lee JY. Synergistic Effect of Intravenous Ibuprofen and Hydromorphone for Postoperative Pain: Prospective Randomized Controlled Trial. Pain Physician. 2016;19:341-8.

24. Zhang J, Troendle J, Reddy UM, et al. Contemporary cesarean delivery practice in the United States. Am J Obstet Gynecol. 2010;203:321-6.

25. Molina G, Weiser TG, Lipsitz SR, et al. Relationship Between Cesarean Delivery Rate and Maternal and Neonatal Mortality. JAMA. 2015;314:2263-70.

26. Tulandi T, Agdi M, Zarei A, Miner L, Sikirica V. Adhesion development and morbidity after repeat cesarean delivery. Am J Obstet Gynecol. 2009;201:51-6.

27. Arlier S, Seyfettinoglu S, Yilmaz E, et al. Incidence of adhesions and maternal and neonatal morbidity after repeat cesarean section. Arch Gynecol Obstet. 2017;295:303-11.

28. Valdes AM, Suokas AK, Doherty SA, Jenkins W, Doherty M. History of knee surgery is associated with higher prevalence of neuropathic pain-like symptoms in patients with severe osteoarthritis of the knee. Semin Arthritis Rheum. 2014:43:588-92.

29. Duan G, Guo S, Zhang Y, et al. The effects of epidemiological factors and pressure pain measurement in predicting postoperative pain: A prospective survey of 1002 Chinese patients. Pain Physician. 2017;20:903-14.

30. De Bonis $M$, Torricelli $M$, Leoni $L$, et al. Carbetocin versus oxytocin after caesarean section: similar efficacy but reduced pain perception in women with high risk of postpartum haemorrhage. J Matern Fetal Neonatal Med. 2012:25:732-5.

31. Rath W. Prevention of postpartum haemorrhage with the oxytocin analogue carbetocin. Eur J Obstet Gynecol Reprod Biol. 2009;147:15-20.

32. Schewe JC, Komusin A, Zinserling J, Nadstawek J, Hoeft A, Hering R. Effects of spinal anaesthesia versus epidural anaesthesia for caesarean section on postoperative analgesic consumption and postoperative pain. Eur J Anaesthesiol. 2009:26:52-9.

33. Booth JL, Harris LC, Eisenach JC, Pan PH. A Randomized Controlled Trial Comparing Two Multimodal Analgesic Techniques in Patients Predicted to Have Severe Pain After Cesarean Delivery. Anesth Analg. 2016;122:1114-9.

34. Kagwa S, Hoeft MA, Firth PG, Ttendo S, Modest VE. Ultrasound guided transversus abdominis plane versus sham blocks after caesarean section in an Ugandan village hospital: a prospective, randomised, double-blinded, single-centre study. Lancet. 2015;385 Suppl 2:S36.

35. Moriyama K, Ohashi Y, Motoyasu A, Ando T, Moriyama K, Yorozu T. Intrathecal Administration of Morphine Decreases Persistent Pain after Cesarean section: A Prospective Observational Study. PLoS One. 2016;11:e155114.

36. Hsu HW, Cheng YJ, Chen LK, et al. Differential analgesic effect of tenoxicam on the wound pain and uterine cramping pain after cesarean section. Clin J Pain. 2003;19:55-8.

37. Yeh YC, Chen SY, Lin CJ, Yeh HM, Sun WZ. Differential analgesic effect of tenoxicam on post-cesarean uterine cramping pain between primiparous and multiparous women. J Formos Med Assoc. 2005;104:647-51.

38. Partlow DB Jr, Chauhan SP, Justice $L$, et al. Diagnosis of postpartum infections: clinical criteria are better than laboratory parameter. J Miss State Med Assoc. 2004;45:67-70.

39. Hartmann KE, Barrett KE, Reid VC, et al. Clinical usefulness of white blood cell count after cesarean delivery. Obstet Gynecol. 2000;96:295-300.

40. Csendes A, Burgos AM, Roizblatt D, Garay C, Bezama P. Inflammatory response measured by body temperature, $C$-reactive protein and white blood cell count 1, 3, and 5 days after laparotomic or laparoscopic gastric bypass surgery. Obes Surg. 2009;19:890-3.

41. Chen SB, Lee YC, Ser KH, et al. Serum C-reactive protein and white blood cell count in morbidly obese surgical patients. Obes Surg. 2009;19:461-6. 
42. Kim SY, Koo BN, Shin CS, Ban M, Han K, Kim MD. The effects of single-dose dexamethasone on inflammatory response and pain after uterine artery embolisation for symptomatic fibroids or adenomyosis: a randomised controlled study. BJOG. 2016:123:580-7.

43. Jin J, Peng L, Chen $\mathrm{Q}$, et al. Prevalence and risk factors for chronic pain following cesarean section: a prospective study. BMC Anesthesiol. 2016;16:99.

44. Dorner TE, Muckenhuber J, Stronegger WJ, Rasky E, Gustorff B, Freidl W. The impact of socio-economic status on pain and the perception of disability due to pain. Eur J Pain. 2011;15:103-9.

45. Ng B, Dimsdale JE, Rollnik JD, Shapiro H. The effect of ethnicity on prescriptions for patient-controlled analgesia for post-operative pain. Pain 1996;66:9-12.

\section{Publisher's Note}

Springer Nature remains neutral with regard to jurisdictional claims in published maps and institutional affiliations.

Ready to submit your research? Choose BMC and benefit from:

- fast, convenient online submission

- thorough peer review by experienced researchers in your field

- rapid publication on acceptance

- support for research data, including large and complex data types

- gold Open Access which fosters wider collaboration and increased citations

- maximum visibility for your research: over $100 \mathrm{M}$ website views per year

At $\mathrm{BMC}$, research is always in progress.

Learn more biomedcentral.com/submissions 